\title{
Atrial Septal Defect/Patent Foramen Ovale and Migraine Headache
}

\author{
Mohammed Tawfiq Numan \\ University of Texas, Houston, Texas \\ USA
}

\section{Introduction}

Migraine headaches affect approximately 13\% of US population, affecting women in a 3:1 ratio and with a $60-80 \%$ familial inheritance. Migraine is a relevant social health problem; in fact it significantly restricts the social life of those who are affected. Recently, migraine headache has been suspected to be a potential risk factor for stroke, particularly in women, smokers and for those making use of oral contraception.

Onset of migraine is usually between the ages of 20-64, with over $80 \%$ having their first episode before age 30 and tends to decrease in middle age. Migraine with aura (MA) is a variant characterized by transient neurological visual, verbal, sensory or motor symptoms that last from five to sixty minutes. MA is also known as "classic migraine" though only $25 \%$ of migraneurs experience an aura.

Increased frequency of patent foramen Ovale (PFO) in migraneurs was first reported in 1998 in a case-control study.

An increased prevalence between patent foramen Ovale (PFOs) and migraine exists but there is conflicting data of a causal relationship between these two conditions. It remains controversial whether cardiac screening and intervention provides a treatment benefit in migraneurs and is an area currently investigated for demonstrating clinical benefit of PFO closure. This topic is an intersection between the practice of primary care physicians, neurologists, and cardiologists on the best practice and management of patients with difficult to control migraines given the billions spent on physician visits and pharmacotherapy.

Several mechanisms linking PFO to migraine have been hypothesized, including humoral causes (serotonin-platelet activation, aggregation, and embolism causing cortical spreading depression) and genetic causes (autosomal dominant inheritance with incomplete penetrance). The presence of a right to left shunt (RLS) may be the most potent trigger of migraine attacks with or without aura, and researchers have speculated that a large RLS may contribute to the high risk of ischemic stroke in migraneurs with PFO.

Diagnostic Modalities to evaluate the presence or absence of PFO in the migraine patients are another controversial subject. Mostly agree that the Trans -thoracic echocardiography is 
less sensitive test particularly in adolescents and adults. Trans- Esophageal and IntraCardiac Echocardiography carry more reliability in detecting left to right shunt. Recently Trans-Cranial Doppler has been postulated as more accurate test to detect the right to left shunting in those patients.

PFO closure (particularly device closure) carries the most controversial issue in this subject. With only -so far- one randomized large clinical trial and several prospective cohorts and case control studies, there is conflicting data about the benefit of PFO closure in relieving or treating the Migraine headache.

This chapter will talk first about the anatomy and physiology of Patent Foramen Ovale in normal population, anatomical variants of the PFO, the current diagnostic methods used by different institutions then seeks to summarize the current literature on the association of PFO and migraine headache and studies that have investigated PFO closure in this population.

\subsection{Definitions}

The topic of Migraine headache in association with Patent Foramen Ovale (PFO) has been one of the controversial topics in the literature. Since 1998 when the first scientific observation that patients with migraine headaches have higher prevelance of $\mathrm{PFO}(1)$, the dogma between causation, association and prevention has continued.

In order to make reading through this chapter easier, some definitions will be instated:

\section{Patent foramen ovale in normal population}

Several studies reported high prevalence of PFO in normal subjects. The highest prevalence reported was in autopsy studies. With a probe inserted in the region of the foremen ovale, if the probe can be passed through it then he/she will be labeled to have PFO. Such studies reported incidence of $25 \%$ (2). While looking for the incidence of PFO in Normal population by Trans Esophageal Echocardiogram reported to be less than autopsy studies about 15\% (3-4).

The foramen ovale is composed of the septum primum and the septum secundum joined in parallel, forming a tunnel-like structure allowing the oxygenated blood from the placenta to pass towards the systemic circulation. Postnatally, it closes with a valve-like mechanism. Patent foramen ovale results from lack of post neonatal closure. Under certain hemodynamic conditions, when there is a transient pressure gradient from the right to left atria, a PFO can open and enable blood or any blood borne substances to pass from the venous to the arterial circulation. This process is the mechanism of paradoxical embolism, which has been frequently reported in the literature (5-8). There are multiple anatomical variants of PFO morphology (figure 1). Occasionally the PFO has an association with atrial septal aneurysm (figure 2). These variants and atrial aneurysm has been believed to play a major role of the amount and the direction of shunt across the PFO.

\section{Migraine headache}

Migraine is a common, disabling, largely inherited neurological disorder with a prevalence of $8 \%$ to $13 \%$ in the population of the Western hemisphere $(9,10)$, with a 3:1 female preponderance. 


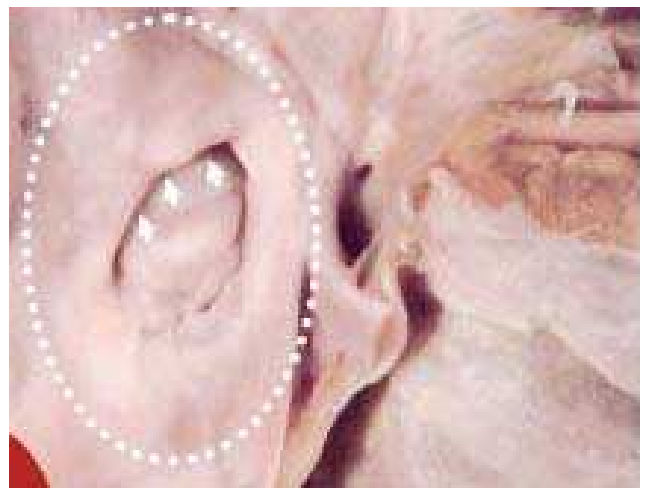

(a)

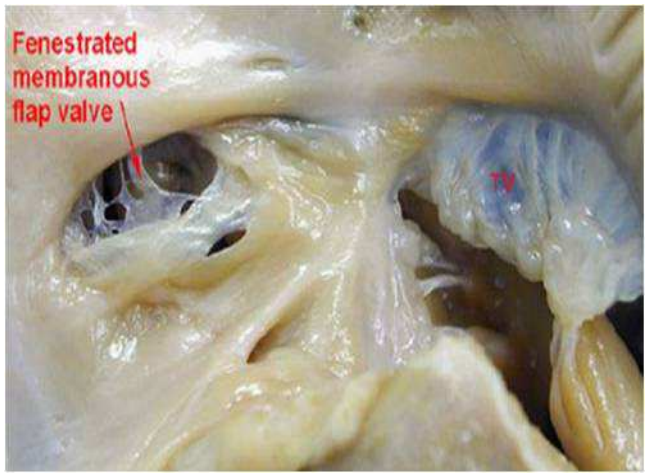

(b)

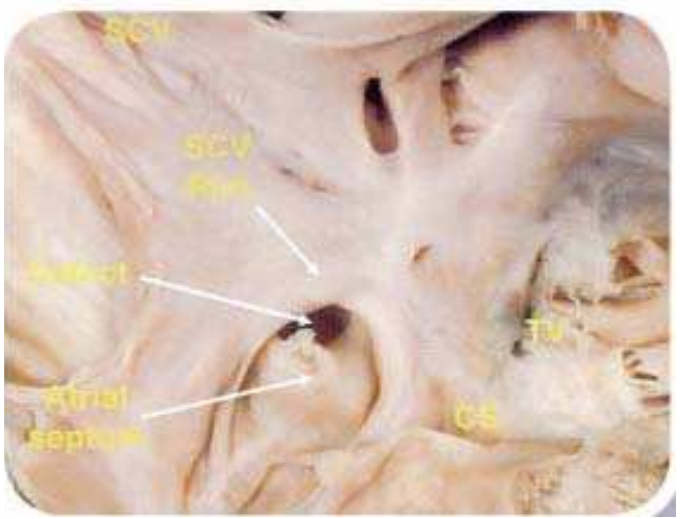

(c)

Fig. 1. Several Morphologies of Patent Foramen Ovale. a: the common type of PFO with a tunnel (white arrows) that can stretch with Valsava. b: Multi fenestration defects in the PFO region. c: a deficient part of the secundum septum covering the PFO from the left side of the atrial septum. 


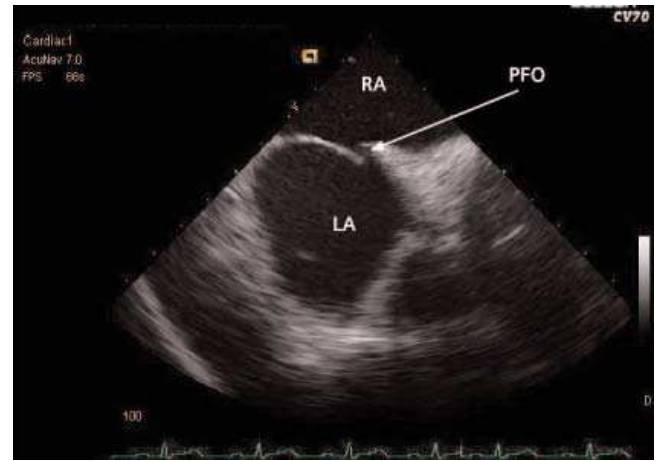

(a)

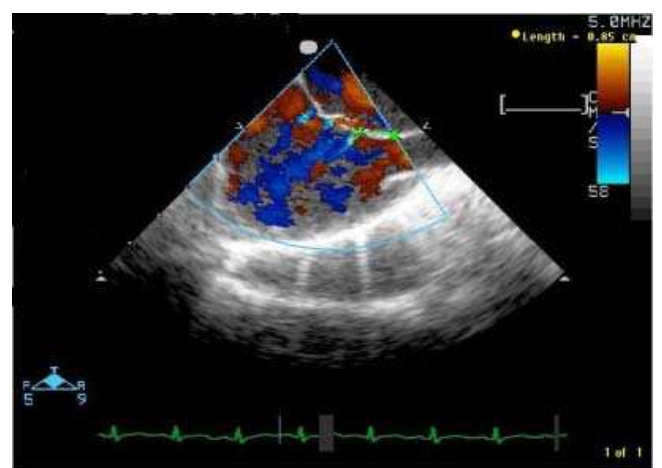

(c)

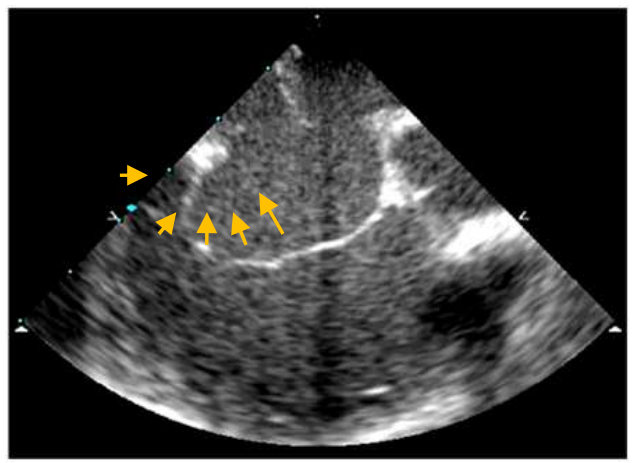

(b)

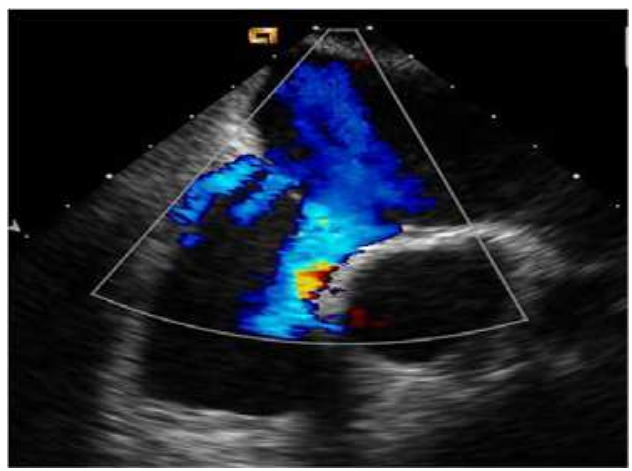

(d)

Fig. 2. Echocardiographic appearance of different PFO morphologies, a: Intra Cardiac Echo (ICE) of a tunnel shape PFO. b: Large atrial aneurysm (orange arrow heads) by trans thoracic echo(TTE). c: small multi fenestration by TTE color Doppler. d: larger fenestrations by TEE color Doppler.

Migraine is a common, chronic, disabling neurovascular disorder characterized by attacks of severe headache, autonomic nervous system dysfunction, and, in some patients, an aura and neurological symptoms (11). The suffering associated with migraine headaches accounts for a significant loss in productivity and a substantial increase in healthcare-related costs. About $60 \%$ of the patients with Migraine reported that they can't go to work while having the headache. In approximately one third of sufferers, an aura-consisting of reversible neurological symptoms such as visual illusions, unilateral paresthesias, and expressive/receptive language dysfunction-will precede or occur during some attacks. A typical migraneurs has one to two attacks per month, with a median duration of 24 hours. In addition, approximately $2 \%$ of the population experiences a more disabling form of migraine, known as chronic migraine, which is characterized by headache on more than 15 days/month.

The diagnosis of migraine is purely clinical, and its physiopathology is complex and not fully understood, with both genetic and environmental factors appearing to play an important role. Genetic effects, including autosomal dominant inheritance with incomplete penetrance $(12,15)$ and coinheritance, $(13)$ have also been reported. 
The prevailing hypothesis regarding the pathogenesis of migraine is an inherited excitability of certain brain networks that, when triggered by particular endogenous or exogenous factors, leads to a cascade of events that result in head pain, in addition to a multitude of other symptoms, including a heightened sensitivity to movement and ambient light, noise, and odor; nausea; emesis; cognitive impairment; vertigo; depression; and lethargy (14). Commonly used preventive medications such as Propranolol, Amitryptiline or anticonvulsants reduce headache frequency in the range of $30-50 \%$, as compared to placebo (16-17).

Migraine occurs in about $15 \%$ of the pediatric population, with approximately

One-third of cases associated with an aura (18).

\subsection{The association of migraine headache and patent foramen ovale}

The initial observation of this association came from the studies of vascular embolic strokes and PFO. The initial observation of increased prevalence of PFO in migraneurs came out in 1998 (1). Then subsequently several studies looked specifically for the prevalence of PFO in Migraneurs. Anzola and colleagues performed a case control study including 113 consecutive patients with migraine with aura, 53 patients with migraine without aura and 25 ages matched no migraine subjects. The presence of PFO was assessed indirectly by using transcranial Doppler sonography with IV. Injection of agitated saline. The prevalence of PFO was $48 \%$ in patients with migraine with aura, $23 \%$ in patients with migraine without aura and $20 \%$ in controls. The difference between migraine with aura and migraine without aura was significant (odds ratio=3.13) as well as between migraine with aura and control group (odds ratio=3.66) (19).

Schwedt et al. (2008) performed a systematic review of 18 out of 134 identified articles to examine the prevalence of migraine in patients with PFO. The results demonstrated that people with migraine with aura are more likely to have a PFO than people with migraine without aura or healthy controls (20). Migraine with aura not related with diving occurred significantly more frequently in patients with large right to left shunt which was present at rest (38 of $80,47.5 \%$ ), compared with patients who had a smaller shunt (four of $40,10 \%$ ) or with patients with no shunt at all (11 of $80,13.8 \%)$. The prevalence of migraine without aura was similar in all groups. Authors concluded that migraine with aura was associated with presence or absence of PFO but also with the shunt size (21).

McCandless et al (2011) conducted pediatric study involved a population consisted of 109 children with migraine; 38 (35\%) with aura and $71(65 \%)$ without aura. The overall PFO prevalence was $35 \%$, similar to the general population ( $35 \%$ vs. $25 \%$; $\mathrm{P}=.13$ ). However, compared with the general population $(25 \%)$, the PFO prevalence was significantly greater in subjects with aura $(50 \%, \mathrm{P}=.0004)$ but similar in those without aura $(27 \%, \mathrm{P}=.73)$. Atrial shunt size was not associated with the presence or absence of aura. Their conclusion was that Children with migraine with aura have a significantly higher prevalence of PFO compared with those without aura or the general population. These data suggest that PFO may contribute to the pathogenesis of migraine with aura in children and have implications for clinical decision making (22).

A meta analysis of 7 studies in adult population with migraine headache and aura showed association of PFO in this particular population ranging from $41-62 \%$ (composite of $56 \%$ by meta-analysis) (23-29). 
On the other hand; NOMAS study (30) involved screening of population from Northern Manhattan area showed no significant association of PFO with Migraine headache population. This study has several limitations though. It included only non-stroke patients who are older than 39 years, they used Trans thoracic Echocardiography for the screen of PFO with no Trans Cranial Doppler evaluation of the bubble study and they depended on self-reporting headache with obvious recall bias.

Table one summarized the major studies of PFO association with Migraine headache. It is clear from all previously mentioned studies that Migraine with Aura has higher association of PFO compared to migraine without aura. Both (with and without aura) has higher prevalence of PFO compared to general population please see Table 1.

$\begin{array}{cccc} & & \text { Migraine With Aura, } & \text { Migraine Without Aura, } \\ \text { Study } & \text { PFO Method } & \mathrm{n} / \mathrm{N}(\%) & \mathrm{n} / \mathrm{N}(\%) \\ \text { Del Sette et al } & \text { TCD } & 18 / 44(41) & \text { NA } \\ \text { Anzola et al } & \text { TCD } & 54 / 113(48) & 12 / 53(23) \\ \text { Schwerzmann et al } & \text { TEE } & 44 / 93(47) & \text { NA } \\ \text { Dalla Volta et al } & \text { TCD } & 161 / 260(62) & 12 / 74(16) \\ \text { Carod-Artal et al } & \text { TCD } & 25 / 48(52) & 32 / 93(34) \\ \text { Domitrz et al } & \text { TCD } & 33 / 61(54) & 15 / 60(25) \\ \text { NOMAS } & \text { TTE } & 26 / 140(19) & 4 / 38(11)\end{array}$

TCD indicates transcranial Doppler; TEE, transesophageal echocardiography.

Table 1. Prevalence of PFO Among Subjects With Migraine Selected From the Literature

The prevailing hypothesis regarding the pathogenesis of migraine is an inherited excitability of certain brain networks that, when triggered by particular endogenous or exogenous factors, leads to a cascade of events that result in head pain. The presence of PFO might trigger this process by allowing substances or metabolites to pass from the hepatic or portal circulation to the carotids circulation. Migraneurs have increased platelet activation and aggregation in response to serotonin. Normally serotonin is metabolized by lung mono amino oxidase (MAO), but if blood is shunted through a PFO and avoids the pulmonary circulation it has been postulated that this can trigger migraine onset and precipitate aura (31). Another mechanism could possibly be transient hypoxemia caused by the PFO, causing subclinical infarcts in the brain, leading to irritation and propensity for migraines. Naqvi et al. report different manifestations of PFO including resting and stress hypoxemia related to left to right shunting across a PFO in the absence of pulmonary hypertension (32).

\section{Results of studies of PFO closure to relief migraine headaches}

Initial observation from studies involves Stroke prevention by PFO device-closure, showed patients with Migraine headaches improve after the procedures (34-38).

Recently Wahl et al (2010) reported a large cohort of Migraneurs (150 patients 96 of them had aura) who underwent closure of PFO for stroke prevention. Of those $34 \%$ showed complete resolution of the headache and $48 \%$ showed significant improvement of their 
headaches, making total of $82 \%$ of the migraneurs benefited from the closure. The presence of aura was associated with higher improvement in their study population. Still they showed improvement in non-aura migraneurs.

Daniela Trabattoni reviewed 305 patients who underwent closure of their PFO for stroke prevention, 77 of them have migraine headache ( $~ 55 \%$ are female). Follow up of these migraine patients at 3 months showed complete cessation of headache in $46 \%$ of the patients and $40 \%$ had improvement of their headache intensity score ( total improvement of $86 \%$ of the patients). They found maintenance of these results up to 5 years of follow up (44).

After these initial observations of improved migraine headache in the patients who underwent prevention of stroke by device-closure of their PFO (table 2), then several studies were conducted primarily for Migraine headaches relief.

\begin{tabular}{|c|c|c|c|c|c|c|c|c|c|}
\hline $\begin{array}{l}\text { Author, year } \\
\text { (Ref.) }\end{array}$ & $\begin{array}{c}\mathrm{N} \\
\text { of pts }\end{array}$ & $\begin{array}{l}\text { Patients } \\
\text { with } \\
\text { migraine }\end{array}$ & $\begin{array}{c}\text { Pts } \\
\text { with } \\
\text { migraine } \\
\text { and aura }\end{array}$ & $\begin{array}{c}\text { Pis } \\
\text { with } \\
\text { migraine } \\
\text { without aura }\end{array}$ & $\begin{array}{c}\text { Age } \\
\text { migraine-pts }\end{array}$ & $\begin{array}{c}\operatorname{Sex}(\mathrm{F} / \mathrm{M}) \\
\text { MH-pts }\end{array}$ & $\begin{array}{l}\text { Indications for } \\
\text { defect closure }\end{array}$ & $\begin{array}{l}\text { Defect } \\
\text { type }\end{array}$ & $\begin{array}{c}\text { Devices } \\
\text { used }\end{array}$ \\
\hline $\begin{array}{l}\text { Anzola, } \\
2006[16]\end{array}$ & 77 & $77(100 \%)$ & $54(70 \%)$ & $23(30 \%)$ & $\begin{array}{l}\text { Between } 36 \pm 11 \\
\text { and } 40 \pm 12 \\
\text { (see text) }\end{array}$ & $58 / 19$ & $\begin{array}{l}\text { Stroke pts and no } \\
\text { stroke pts with } \\
\text { MH (see text) }\end{array}$ & PFO & NA \\
\hline $\begin{array}{l}\text { Morandi, } \\
2003 \text { [18] }\end{array}$ & 17 & $17(100 \%)$ & $8(47 \%)$ & $9(53 \%)$ & $48 \pm 11$ & $12 / 5$ & Stroke & PFO & Amplatzer \\
\hline $\begin{array}{l}\text { Reisman, } \\
2005 \text { [19] }\end{array}$ & 162 & $50(31 \%)$ & $38(76 \%)$ & $12(24 \%)$ & $47 \pm 12$ & $38 / 12$ & Stroke & PFO & $\begin{array}{l}\text { Amplatzer }=11 \\
\text { pts } \\
\text { CardioSeal: } 151 \\
\text { pts }\end{array}$ \\
\hline $\begin{array}{l}\text { Post, } \\
2004 \text { [22] }\end{array}$ & 66 & $26(39 \%)$ & $12(46 \%)$ & $14(54 \%)$ & $55 \pm 10$ & $9 / 17$ & $\begin{array}{l}\text { Stroke and } \\
\text { peripheral } \\
\text { embolism }\end{array}$ & PFO & NA \\
\hline $\begin{array}{l}\text { Schwerzmann, } \\
2004[23]\end{array}$ & 215 & $48(22 \%)$ & $37(77 \%)$ & 11 (23 \%) & $\begin{array}{l}49 \pm 11 \text { MHA } \\
49 \pm 12 \text { MHnoA }\end{array}$ & $31 / 17$ & $\begin{array}{l}\text { Stroke and } \\
\text { decompression } \\
\text { illness }\end{array}$ & PFO & NA \\
\hline $\begin{array}{l}\text { Giardini, } \\
2006[24]\end{array}$ & 131 & 35 (27\%) & 35 (100\%) & $0(0 \%)$ & $45 \pm 13$ & $10 / 25$ & Stroke & PFO & $\begin{array}{l}\text { Amplatzer }=71 \\
\text { pts } \\
\text { CardioSeal }=52 \\
\text { pts } \\
\text { Helex }=8 \text { pts }\end{array}$ \\
\hline $\begin{array}{l}\text { Slavin, } \\
\quad 2007 \text { [25] }\end{array}$ & 131 & $50(42 \%)$ & $40(80 \%)$ & $10(20 \%)$ & $45.7 \pm 11.5$ & $36 / 14$ & Stroke & PFO & $\begin{array}{l}\text { Amplatzer } 101 \\
\text { pts } \\
\text { CardioSeal }=30 \\
\text { pts }\end{array}$ \\
\hline $\begin{array}{l}\text { Dubiel. } \\
2008 \text { [28] }\end{array}$ & 191 & $46(24 \%)$ & $24(52 \%)$ & $22(48 \%)$ & $44 \pm 13.5$ & $35 / 11$ & Stroke & PFO & $\begin{array}{l}\text { Amplatzer }=38 \\
\text { pts Cardio- } \\
\text { SEAL } / \text { Starflex } \\
=8 \mathrm{pts}\end{array}$ \\
\hline $\begin{array}{l}\text { MIST, } \\
2008 \text { [29] }\end{array}$ & 147 & $74(100 \%)$ & $74(100 \%)$ & $0(\%)$ & $44.6 \pm 10.6$ & $12 / 62$ & $\begin{array}{l}\text { Migraine with } \\
\text { aura }\end{array}$ & PFO & Starflex $=74 \mathrm{pt}$ \\
\hline $\begin{array}{l}\text { Jesurum, } \\
2008 \text { [30] }\end{array}$ & 77 & $77(100 \%)$ & $55(71 \%)$ & $22(29 \%)$ & $\begin{array}{l}47 \pm 12 \mathrm{MHA} \\
46 \pm 10 \mathrm{MhnoA}\end{array}$ & $57 / 20$ & $\begin{array}{l}\text { Stroke or } \\
\text { paradoxical } \\
\text { embolism }\end{array}$ & PFO & $\begin{aligned} & \text { CardioSeal }=67 \\
& \text { pts } \\
& \text { Amplatzer }=10 \\
& \text { pts }\end{aligned}$ \\
\hline $\begin{array}{l}\text { Luermans, } \\
2008 \text { [31] }\end{array}$ & 92 & $24(28,6 \%)$ & $10(42 \%)$ & $14(58 \%)$ & $51.6 \pm 12.3$ & $9 / 15$ & $\begin{array}{l}\text { Stroke or } \\
\quad \text { paradoxical } \\
\text { embolism }\end{array}$ & PFO & $\begin{array}{l}\text { Amplatzer }=7 \\
\text { pts } \\
\text { CardioSeal } / \text { Star- } \\
\text { flex }=42 \text { pts } \\
\text { Cardiastar }=38 \\
\text { pts } \\
\text { Helex }=2 \text { pts }\end{array}$ \\
\hline Total & 1,306 & $524(40 \%)$ & $387(74 \%)$ & $137(26 \%)$ & & & & & \\
\hline
\end{tabular}

Table 2. Meta Analysis of 11 studies reported by Gianfranco Butera et al (40) 
Luciane Piazza et al. evaluated 42 patients with migraine headache (28 with aura and 14 without aura) after PFO closure for the migraine headache as a primary reason. After 6 months follow up they found complete resolution of the migraine in $26 \%$, and significant improvement in $52 \%$ of the study group. Interestingly they found patients improvement (total 78\%) regardless of the presence of aura history. Multiple logistic regression analysis showed that the improvement in migraine with aura and migraine without aura was independent of migraine type, sex, age, cerebrovascular risk factors and cerebrovascular events, type of cardiac defect, and thrombophilic conditions (41).

Another study by Andreas Wahl and his group was conducted on 17 patients with Migraine headache underwent closure of the PFO primarily for the headache reason (no stroke). They found total improvement in $71 \%$ of their patients with complete resolution of the headache in $26 \%$. Their follow up was up to 30 months. They found slightly higher improvement in patients with aura (42).

Gianluca Rigatelli et al. conducted prospective study on 34 patients with Migraine headache (22 females and 12 male) and underwent closure of the atrial defect by one of two devices (Amplatz cribriform, AGA PFO device or Premere Occlusion System). They found about $55 \%$ of their study group have moderate to large atrial septal aneurysm. After a median of 9 months follow up period they have significant improvement in all the patients with 20 patients stopped completely their anti headache medications and the rest have improvement with less number of their medications (43).

The only randomized prospective study with patients blinded for PFO closure conducted for migraine headache is MIST trial. They included about 147 patients randomized for device closure or Sham procedure (patients will have general anesthesia with incision in the groin without device implantation). The study had an ambitious primary end point which was complete cessation of Migraine headache in $40 \%$ of the patients who receive PFO device closure. They chose STARFlex ${ }^{\circledR}$ and they have much higher rate of complications in their study $(\sim 12 \%)$ compared to other PFO device studies. They showed in 6 months no statistical difference between the two groups in complete cessation of Migraine headache. Post-hoc analysis revealed that, when two extreme outliers were removed, a significant reduction in the median total headache days was observed in patients assigned to PFO closure $(P=0.027)$. A number of methodological reasons could explain why the primary end point of the MisT trial was not achieved. First, this ambitious primary end point, presumably selected to justify the risks of an interventional procedure, was so strict as to be unrealistic, and was arguably less clinically relevant than a quantifiable reduction in headache days. Although the path physiology of migraine is not fully elucidated, the probable multifactorial nature of migraine triggers means that correction of one potential trigger is unlikely to result in headache cure. Second, the patients for whom migraine improvement was previously reported had PFO closure for either cryptogenic stroke or decompression illness. However, such patients were specifically excluded from the MIST trial. The amount of residual shunt in MIST trial was extremely high $(\sim 35 \%)$ in 6 months follow up probably due to inherent device limitations used in the study. Other potential confounding factors include the 'hangover effect' of antiplatelet therapy and the difficulty of distinguishing between cardiac-level and pulmonary-level shunt when using transthoracic echocardiography (TTE). nonetheless, as the first randomized, controlled trial of its kind, the MIST trial has pioneered a robust study design for PFO closure trials and raised questions to be addressed in future studies. 
In Summery: The association of migraine headache with Patent Foramen Ovale is higher than normal population (more than double) by most of the studies. Trans Cranial Doppler has higher sensitivity than Echo (TTE, TEE or ICE) in detecting the right to left shunt across the atrial septum. Because of the anatomical orientation of the Inferior Vena Cava towards the Foramen Ovale, injection of bubble contrast in lower limbs veins might be higher sensitive than injection in upper limbs veins. Whether the PFO/Migraine association means also a causation relationship: a question still needs more definite answer. Most of the studies (from stroke studies and primary studies for Migraine relief) are pointing towards the causation relationship. Although the only randomized prospective study in the literature failed to show a definite answer, several confounding factors (as mentioned above in the text) can explain the negativity of this study. Most of the studies showed higher response and benefit to patients suffer from Migraine with aura compared to others.

\section{References}

[1] Del Sette M, Angeli S, Leandri M, Ferriero G, Bruzzone GL, Finocchi C, Gandolfo C. Migraine with aura and right-to-left shunt on transcranial Doppler: a case control study. Cerebrovasc Dis. 1998;8:327-330.

[2] Hagen PT, Scholz DG, Edwards WD. Incidence and size of patent foramen ovale during the first 10 decades of life: an autopsy study of 965 normal hearts. Mayo Clin Proc. 1984;59:17-20.

[3] Di Tullio MR, Sacco RL, Sciacca RR, Jin Z, Homma S. Patent foramen ovale and the risk of ischemic stroke in a multiethnic population. J Am Coll Cardiol. 2007;49:797- 802.

[4] Meissner I, Whisnant JP, Khanderia BK, Spittell PC, O'Fallon WM, Pascoe RD, EnriquezSarano M, Seward JB, Covalt JL, Sicks JD, Wiebers DO. Prevalence of potential risk factors for stroke assessed by transesophageal echocardiography and carotid ultrasonography: the SPARC study Stroke Prevention: Assessment of Risk in a Community. Mayo Clin Proc. 1999;74:862- 869.

[5] Choong, C. K. et al. Life-threatening impending paradoxical embolus caught "redhanded": successful management by multidisciplinary team approach. J. Thorac. Cardiovasc. Surg. 136, 527-528 (2008).

[6] Kim, R. J. \& Girardi, L. N. "Lots of clots": multiple thromboemboli including a huge paradoxical embolus in a 29-year old man. Int. J. Cardiol. 129, e50-e52 (2008).

[7] Madani, H. \& Ransom, P. A. Paradoxical embolus illustrating speed of action of recombinant tissue plasminogen activator in massive pulmonary embolism. Emerg. Med. J. 24, 441 (2007).

[8] Ahmed, S., Sadiq, A., Siddiqui, A. K., Borgen, E. \& Mattana, J. Paradoxical arterial emboli causing acute limb ischemia in a patient with essential thrombocytosis. Am. J. Med. Sci. 326, 156-158 (2003).

[9] Lipton RB, Bigal ME, Diamond M, Freitag F, Reed ML, Stewart WF. Migraine prevalence, disease burden, and the need for preventative therapy. Neurology 2007;68:343-9.

[10] Stovner LJ, Hagen K, Jensen R, et al. The global burden of headache: a documentation of headache prevalence and disability worldwide. Cephalalgia 2007;27:193-210.

[11] Goadsby PJ, Lipton RB, Ferrari MD. Migraine: current understanding and treatment. N Engl J Med. 2002;346:257-270. 
[12] Wilmshurst PT, Pearson MJ, Nightingale S, Walsh KP, Morrison WL. Inheritance of persistent foramen ovale and atrial septal defects and the relation to familial migraine with aura. Heart. 2004;90:1315-1320.

[13] Del Sette M, Angeli S, Leandri M, Ferriero G, Bruzzone GL, Finocchi C, Gandolfo C. Migraine with aura and right-to-left shunt on transcranial Doppler: a case control study. Cerebrovasc Dis. 1998;8:327-330.

[14] Charles A. Advances in the basic and clinical science of migraine. Ann Neurol 2009;65:491-8.

[15] Wilmshurst PT, Pearson MJ, Nightingale S, et al. Inheritance of persistent foramen ovale and atrial septal defects and the relation to familial migraine with aura. Heart 2004;90:1315-20.

[16] Lipton RB, Bigal ME, Diamond M, Freitag F, Reed ML, Stewart WF. Migraine prevalence, disease burden, and the need for preventative therapy. Neurology 2007;68:343-9.

[17] Stovner LJ, Hagen K, Jensen R, et al. The global burden of headache: a documentation of headache prevalence and disability worldwide. Cephalalgia 2007;27:193-210.

[18] Abu-Arefeh I, Russell G. Prevalence of headache and migraine in schoolchildren. BMJ 1994;309:765-9.

[19] Anzola GP, Frisoni GB, Morandi E, et al. Shunt associated migraine responds favorably to atrial septal repair: a case control study. Stroke 2006;37:430-4.

[20] Schwedt TJ, Demaerschalk BM, Dodick DW. Patent foramen ovale and migraine: a quantitative systematic review. Cephalalgia 2008;28:531-40.

[21] Wilmshurst PT, Nightingale S, Walsh KP, et al. Effect on migraine of closure of cardiac right-to-left shunts to prevent recurrence of decompression illness or stroke or for haemodynamic reasons. Lancet 2000;356:1648-51.

[22] Rachel T. McCandless, MD, Cammon B. Arrington, MD, Douglas C. Nielsen, James F. Bale, Jr., MD, and L. LuAnn Minich, MD. Patent Foramen Ovale in Children with Migraine Headaches. J Pediatr 2011;159:243-7.

[23] Agmon Y, Khandheria BK, Meissner I, Gentile F, Sicks JD, O'FallonWM, et al. Comparison of frequency of patent foramen ovale by transesophageal echocardiography in patients with cerebral ischemic events versus in subjects in the general population. Am J Cardiol 2001;88:330-2.

[24] Del Sette M, Angeli S, Leandri M, Ferriero G, Bruzzone GL, Finocchi C, Gandolfo C. Migraine with aura and right-to-left shunt on transcranial Doppler: a case-control study. Cerebrovasc Dis 1998;8:327-30.

[25] Anzola GP, Magoni M, Guindani M, Rozzini L, Dalla Volta G. Potential source of cerebral embolism in migraine with aura: a transcranial Doppler study. Neurology 1999;52:1622-5.

[26] Domitrz I, Mieszkowski J, Kaminska A. Relationship between migraine and patent foramen ovale: a study of 121 patients with migraine. Headache 2007;47:1311-8.

[27] Schwerzmann M, Nedeltchev K, Lagger F, Mattle HP, Windecker S, Meier B, Seiler C. Prevalence and size of directly detected patent foramen ovale in migraine with aura. Neurology 2005;65:1415-8.

[28] Schwerzmann M, Nedeltchev K, Meier B. Patent foramen ovale closure: a new therapy for migraine. Catheter Cardiovasc Interv 2007;69:277-84. 
[29] Garg P, Servoss SJ, Wu JC, Bajwa ZH, Selim MH, Dineen A, et al. Lack of association between migraine headache and patent foramen ovale: results of a case-control study. Circulation 2010;121:1406-12.

[30] Tatjana Rundek, Mitchell S.V. Elkind, Marco R. Di Tullio, Emmanuel Carrera, Zhezhen Jin, Ralph L. Sacco and Shunichi Homma. Northern Manhattan Study (NOMAS) Patent Foramen Ovale and Migraine : A Cross-Sectional Study From the Northern Manhattan Study (NOMAS). Circulation 2008, 118:1419-1424

[31] Zeller JA, Frahm K, Baron R, et al: Platelet-Leukocyte Interaction and Platelet Activation in Migraine: A link to ischemic stroke? J Neurol Neurosurg Psychiatry 2004;75:984-987.

[32] Naqvi T, Rafie R, Daneshvar S: Potential Faces of Patent Foramen Ovale. Echocardiogr 2010;27:897-907.

[33] Wilmshurst PT, Nightingale S, Walsh KP, et al. Effect on migraine of closure of cardiac right-to-left shunts to prevent recurrence of decompression illness or stroke or for haemodynamic reasons. Lancet 2000;356:1648-51.

[34] Schwerzmann M, Wiher S, Nedeltchev K, et al. Percutaneous closure of patent foramen ovale reduces the frequency of migraine attacks. Neurology 2004;62:1399-401.

[35] Post MC, Thijs V, Herroelen L, et al. Closure of a patent foramen ovale is associated with a decrease in prevalence of migraine. Neurology 2004;62:1439-40.

[36] Azarbal B, Tobis J, Suh W, et al. Association of interatrial shunts and migraine headaches: impact of transcatheter closure. J Am Coll Cardiol 2005;45:489-92.

[37] Reisman M, Christofferson RD, Jesurum J, et al. Migraine headache relief after transcatheter closure of patent foramen ovale. J Am Coll Cardiol 2005;45:493-5.

[38] Giardini A, Donti A, Formigari R, et al. Transcatheter patent foramen ovale closure mitigates aura migraine headaches abolishing spontaneous right-to-left shunting. Am Heart J 2006;151:922

[39] Andreas Wahl, Fabien Praz, Tony Tai, Oliver Findling, Nazan Walpoth, Krassen Nedeltchev, Markus Schwerzmann, Stephan Windecker, Heinrich P Mattle, Bernhard Meier. Improvement of migraine headaches after percutaneous closure of patent foramen ovale for secondary prevention of paradoxical embolism. Heart 2010; 96:967-973.

[40] Gianfranco Butera, Giuseppe G. L. Biondi-Zoccai, Mario Carminati, Luigi Caputi, Susanna Usai, Gennaro Bussone, Giovanni Meola, Angelica Bibiana Delogu, Imad Sheiban and Giuseppe Sangiorgi. Systematic Review and Meta-Analysis of Currently Available Clinical Evidence on Migraine and Patent Foramen Ovale Percutaneous Closure: Much Ado About Nothing? Catheterization and Cardiovascular Interventions 75:494-504 (2010)

[41] Massimo Chessa, Chiara Colombo, Gianfranco Butera, Diana Negura, Luciane Piazza, Leonardo Varotto, Claudio Bussadori, Vlasta Fesslova, Giovanni Meola and Mario Carminati. Is it too early to recommend patent foramen ovale closure for all patients who suffer from migraine? A single-centre study. Journal of Cardiovascular Medicine 2009, 10:401-405

[42] Andreas Wahl, Fabien Praz, Oliver Findling, Krassen Nedeltchev, Markus Schwerzmann, Tony Tai, Stephan Windecker, Heinrich P. Mattle, and Bernhard Meier. Percutaneous Closure of Patent Foramen Ovale for Migraine Headaches Refractory to Medical Treatment. Catheterization and Cardiovascular Interventions 74:124-129 (2009) 
[43] Gianluca Rigatelli, Paolo Cardaioli, Fabio Dell'Avvocataa, Massimo Giordan, Gabriele Braggion, Mauro Chinaglia, Loris Roncon. Transcatheter patent foramen ovale closure is effective in reducing migraine independently from specific interatrial septum anatomy and closure devices design. Cardiovascular Revascularization Medicine 11 (2010) 29-33

[44] Daniela Trabattoni, Franco Fabbiocchi, Piero Montorsi, Stefano Galli, Giovanni Teruzzi, Luca Grancini, Pamela Gatto, and Antonio L. Bartorelli. Sustained Long-Term Benefit of Patent Foramen Ovale Closure on Migraine. Catheterization and Cardiovascular Interventions 77:570-574 (2011) 


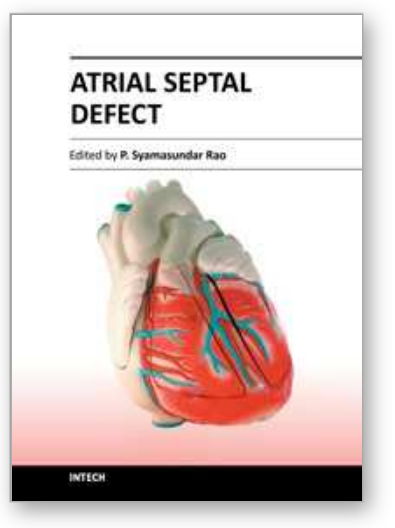

\author{
Atrial Septal Defect \\ Edited by Dr. P. Syamasundar Rao
}

ISBN 978-953-51-0531-2

Hard cover, 184 pages

Publisher InTech

Published online 25, April, 2012

Published in print edition April, 2012

Atrial Septal Defects (ASDs) are relatively common both in children and adults. Recent reports of increase in the prevalence of ASD may be related use of color Doppler echocardiography. The etiology of the ASD is largely unknown. While the majority of the book addresses closure of ASDs, one chapter in particular focuses on creating atrial defects in the fetus with hypoplastic left heart syndrome. This book, I hope, will give the needed knowledge to the physician caring for infants, children, adults and elderly with ASD which may help them provide best possible care for their patients.

\title{
How to reference
}

In order to correctly reference this scholarly work, feel free to copy and paste the following:

Mohammed Tawfiq Numan (2012). Atrial Septal Defect/Patent Foramen Ovale and Migraine Headache, Atrial Septal Defect, Dr. P. Syamasundar Rao (Ed.), ISBN: 978-953-51-0531-2, InTech, Available from:

http://www.intechopen.com/books/atrial-septal-defect/atrial-septal-defect-patent-foramen-ovale-and-migraineheadache

\section{INTECH}

open science | open minds

\section{InTech Europe}

University Campus STeP Ri

Slavka Krautzeka 83/A

51000 Rijeka, Croatia

Phone: +385 (51) 770447

Fax: +385 (51) 686166

www.intechopen.com

\section{InTech China}

Unit 405, Office Block, Hotel Equatorial Shanghai

No.65, Yan An Road (West), Shanghai, 200040, China

中国上海市延安西路65号上海国际贵都大饭店办公楼 405 单元

Phone: +86-21-62489820

Fax: +86-21-62489821 
(C) 2012 The Author(s). Licensee IntechOpen. This is an open access article distributed under the terms of the Creative Commons Attribution 3.0 License, which permits unrestricted use, distribution, and reproduction in any medium, provided the original work is properly cited. 